\title{
Current Practices in Treating Cardiomyopathy and Heart Failure in Duchenne Muscular Dystrophy (DMD): Understanding Care Practices in Order to Optimize DMD Heart Failure Through ACTION
}

\author{
Chet Villa ${ }^{1}$ (D) Scott R. Auerbach ${ }^{2} \cdot$ Neha Bansal $^{3} \cdot$ Brian F. Birnbaum $^{4}$. Jennifer Conway ${ }^{5}$. Paul Esteso ${ }^{6}$. \\ Katheryn Gambetta ${ }^{7}$. E. Kevin Hall ${ }^{8}$. Beth D. Kaufman ${ }^{9}$. Sonya Kirmani ${ }^{10}$ - Ashwin K. Lal ${ }^{11}$ • Hugo R. Martinez ${ }^{12}$. \\ Deipanjan Nandi ${ }^{13}$. Matthew J. O'Connor ${ }^{14}$. John J. Parent ${ }^{15}$. Frank J. Raucci ${ }^{16}$. Renata Shih ${ }^{17}$. Svetlana Shugh ${ }^{18}$. \\ Jonathan H. Soslow ${ }^{19} \cdot$ Hari Tunuguntla ${ }^{20} \cdot$ Carol A. Wittlieb-Weber ${ }^{14} \cdot$ Kathi Kinnett $^{21} \cdot$ Linda Cripe $^{13}$
}

Received: 17 November 2021 / Accepted: 17 December 2021 / Published online: 13 January 2022

(c) The Author(s), under exclusive licence to Springer Science+Business Media, LLC, part of Springer Nature 2022

\begin{abstract}
Cardiac disease has emerged as a leading cause of mortality in Duchenne muscular dystrophy in the current era. This survey sought to identify the diagnostic and therapeutic approach to DMD among pediatric cardiologists in Advanced Cardiac Therapies Improving Outcomes Network. Pediatric cardiology providers within ACTION (a multi-center pediatric heart failure learning network) were surveyed regarding their approaches to cardiac care in DMD. Thirty-one providers from 23 centers responded. Cardiac MRI and Holter monitoring are routinely obtained, but the frequency of use and indications for ordering these tests varied widely. Angiotensin converting enzyme inhibitor and aldosterone antagonist are generally initiated prior to onset of systolic dysfunction, while the indications for initiating beta-blocker therapy vary more widely. Seventeen (55\%) providers report their center has placed an implantable cardioverter defibrillator in at least 1 DMD patient, while 11 providers (35\%) would not place an ICD for primary prevention in a DMD patient. Twenty-three providers $(74 \%)$ would consider placement of a ventricular assist device (VAD) as destination therapy $(n=23,74 \%)$ and three providers $(10 \%)$ would consider a VAD only as bridge to transplant. Five providers (16\%) would not consider VAD at their institution. Cardiac diagnostic and therapeutic approaches vary among ACTION centers, with notable variation present regarding the use of advanced therapies (ICD and VAD). The network is currently working to harmonize medical practices and optimize clinical care in an era of rapidly evolving outcomes and cardiac/skeletal muscle therapies.
\end{abstract}

Keywords Duchenne muscular dystrophy $\cdot$ Cardiomyopathy $\cdot$ Heart failure

$\begin{array}{ll}\text { Abbreviations } \\ \text { ACEi } & \text { Angiotensin-converting enzyme inhibitor } \\ \text { ACTION } & \begin{array}{l}\text { Advanced Cardiac Therapies Improving Out } \\ \text { comes Network }\end{array} \\ \text { ARB } & \text { Angiotensin receptor blocker } \\ \text { ARNI } & \text { Angiotensin receptor neprilysin inhibitor } \\ \text { CMR } & \text { Cardiac MRI } \\ \text { CINRG } & \text { Cooperative International Neuromuscular } \\ & \text { Research Group } \\ \text { DMD } & \text { Duchenne muscular dystrophy } \\ \text { ICD } & \text { Implantable cardioverter defibrillators } \\ \text { LGE } & \text { Late gadolinium enhancement }\end{array}$

Chet Villa

Chet.villa@cchmc.org

Extended author information available on the last page of the article
LVEF Left ventricular ejection fraction

VAD Ventricular assist devices

\section{Introduction}

The last three decades have seen incremental improvements in long term survival of boys and men with Duchenne muscular dystrophy (DMD) [1,2]. This has been driven by clinical improvements in neuromuscular and pulmonary clinical care such that life expectancy now reaches the third or fourth decade of life [3]. Early initiation and consistent use of glucocorticoids has prolonged the time to loss of ambulation, while aggressive pulmonary toilet practices and initiation of non-invasive respiratory support has significantly decreased the frequency of early, respiratory-related mortality [4]. These clinical gains have improved overall survival, but have 
"unmasked" the long term progression of cardiomyopathy to heart failure. Cardiac disease now accounts for $~ 30-50 \%$ of DMD-related mortality $[5,6]$. These mortality rates have led to sequential consensus guidelines discussing the evolving outcomes, diagnostic protocols, and approaches to medical therapy. [7-9] These guidelines and consensus statements have also called for data regarding the use of advanced cardiac therapies such as implantable cardioverter defibrillators (ICD) and ventricular assist devices (VAD).

Despite these recommendations, and recent data suggesting cardiac disease progression may be modified through medical management, the indications for employing medical and advanced therapies remains heterogenous and generally insufficient $[5,6,10-13]$. Only $43 \%$ of participants in the Cooperative International Neuromuscular Research Group (CINRG) with ventricular dysfunction were on any cardiac medications, and a recent multi-center study demonstrated only $57 \%$ of patients with severe dysfunction were on both an angiotensin-converting enzyme inhibitor (ACEi)/ angiotensin receptor blocker (ARB) and a beta-blocker [13, 14]. Data regarding the indications for employing advanced cardiac therapies and the outcomes associated with those therapies remain limited [13].

The Advanced Cardiac Therapies Improving Outcomes Network (ACTION), is a 50 institution, international, quality improvement network which formed in 2017 and is focused on improving clinical outcomes in children and young adults with heart failure [15]. The network formed a DMDrelated committee in October 2019 with the stated goal of improving symptom-free cardiac outcomes in patients with DMD. As part of that goal, we sought to describe the current approach to cardiac diagnostics, medical management, and advanced cardiac therapies among participating centers in order to assess the baseline state of medical practice and identify areas for improvement. Herein we also describe the ongoing projects and future directions of the group.

\section{Methods}

ACTION learning network members with an interest in DMD were invited to participate in a survey in November 2019 as the ACTION DMD committee was forming. The survey sought to describe current cardiac diagnostic approaches and clinical management across the centers. A total of 31 cardiology providers directly involved with DMD care, from 22 distinct centers (Table 1), responded. Multiple providers from a given center could respond given that care is not always centralized, and the indications for heart failure therapies are driven by both personal preferences and centerspecific protocols. The survey was distributed electronically and administered via the Web site www.surveymonkey. com. Individual clinician details remained anonymous, but
Table 1 List of ACTION centers who contributed to the survey

C.S. Mott Children's Hospital
Children's Hospital Colorado
Children's Hospital at Montefiore
Children's Hospital of Los Angeles
Children's Hospital of Philadelphia
Children's Mercy Kansas City
Children's National Hospital
Cincinnati Children's Hospital
Duke Children's Hospital
Golisano Children's Hospital
Joe DiMaggio Children's Hospital
LeBonheur Children's Hospital
Lucille Packard Children's Hospital
Lurie Children's Hospital
Nationwide Children's Hospital
Ochsner Medical Center
Primary Children's Hospital
Riley Children's Hospital
Shand's Children's Hospital
St. Louis Children's Hospital
Stollery Children's Hospital
Texas Children's Hospital
Yale New Haven Children's Hospital

providers were asked to provide their center name. Data are presented in a descriptive manner. The study was under an Institutional Review Board exempt protocol as part of the ACTION quality improvement process.

\section{Results}

\section{Center Characteristics}

A total of 31 providers responded from at least 23 centers ( 3 providers opted not to disclose their institution). Just over half of providers $(n=17,54 \%)$ are from centers that see $>50$ patients per year. The remaining respondents evaluate between 21 and 50 patients $(n=10,32 \%)$ and $11-20$ patients $(n=4,13 \%)$ per year. Cardiac care is most commonly provided by a limited number of cardiologists ( 3 or less providers) in each center $(n=24,77 \%)$, and is delivered as part of a multi-disciplinary clinic $(n=28,90 \%)$.

\section{Clinical Evaluation}

Among the 31 respondents, 28 (90\%) noted that patients are seen by a cardiologist at the time of diagnosis. The frequency of evaluation for a child $<10$ years of age was relatively variable with 10 respondents (32\%) noting patients are seen 
every 2 years, 16 respondents (52\%) seeing patients yearly, and 5 respondents (16\%) seeing patients every 6 months. Patients $>10$ years of age are generally seen in 12 month $(n=11,35 \%)$ or 6 month increments $(n=20,65 \%)$.

\section{Diagnostic Evaluation}

\section{CMR}

Cardiac MRI (CMR) is generally employed by a majority of providers as part of their clinical evaluation $(n=27,87 \%)$, although the frequency of use is highly variable and provider dependent. The majority of providers routinely obtain a CMR by 10 years of age $(n=17,55 \%)$, with the remaining providers who utilize CMR obtaining imaging by age 13 $(n=10,32 \%)$. The majority of centers avoid sedation for CMR, with only 2 respondents (6\%) utilizing sedation, if required. A total of 13 providers (42\%) incorporate serial CMR with six providers (19\%) imaging with CMR yearly and 7 providers (23\%) every 2 years. The remaining providers had variable imaging indications and frequency of use. Gadolinium is typically used with each study, although 4 providers (13\%) note that gadolinium is no longer administered, or done so with decreased frequency, after late gadolinium enhancement (LGE) is first noted.

\section{Electrophysiologic Monitoring}

A significant majority of providers routinely employ Holter monitoring ( $n=26,84 \%)$, although there is significant heterogeneity in the indications and frequency of screening Holter in the absence of cardiac symptoms. Eight providers (26\%) begin screening once LVEF is $<55 \%$. Two of these eight providers supplement function-based indications with additional age cutoffs and would begin screening by age 10 and 15 if dysfunction is not already present. Two providers (6\%) initiate Holter monitoring after LVEF falls below 50\%, 3 providers (10\%) initiate after LVEF falls below 40-45\% and 3 providers (10\%) after the LVEF is $<35 \%$. Six providers (19\%) initiate based on age alone and do so between 10 and 13. The remaining providers initiate based on persistent sinus tachycardia $(n=1,6 \%)$, presence of ectopy on EKG/ exam $(n=2,6 \%)$, or left atrial enlargement $(n=1,3 \%)$.

\section{Clinical Management}

\section{Medication Use}

Patient blood pressure goals are generally based on age, gender, and height recommendations, although 7 providers (23\%) noted they will tolerate lower blood pressures (systolic blood pressure $<90 \mathrm{mmHg}$ ) in older patients if they are non-ambulatory and asymptomatic.
Angiotensin Converting Enzyme Inhibitor (ACEi)/ Angiotensin Receptor Blocker (ARB)

All providers surveyed employ ACEi/ARB as a routine component of therapy, with the majority $(n=21,68 \%)$ initiating therapy at age 10, if systolic dysfunction is not already present (Fig. 1a). Seven of the 31 providers (23\%) would also initiate therapy based on the presence of late gadolinium enhancement (LGE) on CMR independent of age or systolic dysfunction (alternately defined as LVEF $<55 \%$ or LVEF $<50 \%$ ).

A total of 7 providers (23\%) do report using an angiotensin receptor neprolysin inhibitor (ARNI). These centers report initiating ARNI therapy when LVEF falls below $<40-45 \%$ or when moderate systolic dysfunction is present qualitatively.

\section{Beta-Blockers (BB)}

All providers surveyed employ BB as a routine component of therapy and the majority of centers $(n=21,68 \%)$ initiate therapy when systolic dysfunction develops (alternately defined as $\mathrm{LVEF}<55 \%$, $\mathrm{LVEF}<50 \%$, or by qualitative assessment of dysfunction) (Fig. 1b). Four of the 31 providers (13\%) initiate therapy when late gadolinium enhancement (LGE) is detected on CMR independent of systolic function (alternately defined as LVEF $<55 \%$ or $\mathrm{LVEF}<50 \%$, as per ACEi/ARB above). The remaining 6 providers initiated therapy when more significant dysfunction was present (alternately defined as LVEF $<45 \%,<40 \%,<35 \%$, or moderate dysfunction qualitatively).

\section{Aldosterone Antagonists}

Twenty-eight of 31 providers (90\%) routinely utilize aldosterone antagonists (Fig. 1c). Nine providers (29\%) initiate based on the presence of LGE on CMR and another 9 providers (29\%) initiate if either LGE or systolic dysfunction is present. Seven providers (23\%) initiate aldosterone antagonists based on the presence of systolic dysfunction, although the degree of dysfunction required was variable ranging from any systolic dysfunction to an LVEF $<35 \%$. Three providers (10\%) initiate prophylactically at age 10 .

\section{Advanced Cardiac Therapy Use and Consideration}

\section{Implantable Cardioverter Defibrillator (ICD)}

Seventeen of 31 (55\%) providers report their center has placed an ICD in at least 1 DMD patient, while 11 providers (35\%) note that ICDs are never considered for primary prevention in DMD at their institution. The most common indication $(n=8,26 \%)$ for considering ICD placement among 
Fig. 1 Provider indications for initiating cardiac therapy by medication class: a Angiotensin converting enzyme inhibitor/ angiotensin receptor blocker; b Beta-blocker; c Aldosterone antagonist. ACEi Angiotensin converting enzyme inhibitor, $A R B$ Angiotensin receptor blocker, $L G E$ Late gadolinium enhancement a

Indications for initiating ACEi/ARB

Age 10 or mild systolic dysfunction

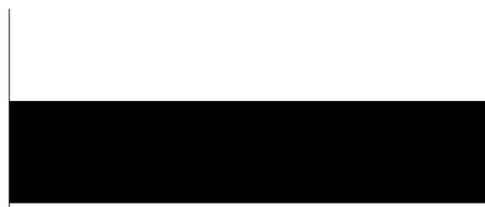

$68 \%$

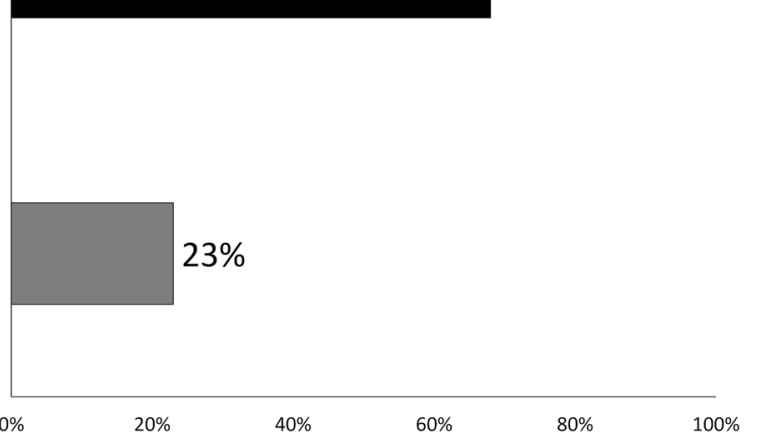

b

Indications for initiating beta-blockers

Mild systolic dysfunction

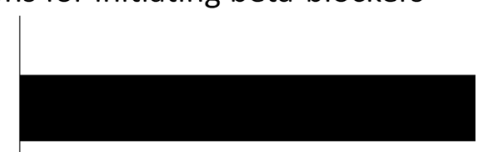

$68 \%$

Moderate or worse systolic dysfunction

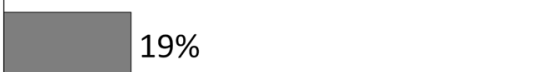

Systolic dysfunction or LGE

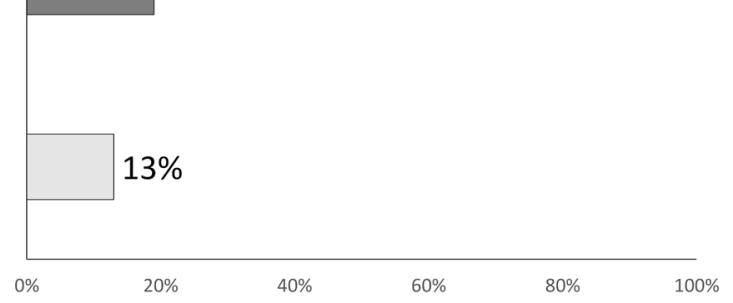

C

Indications for initiating aldosterone antagonists

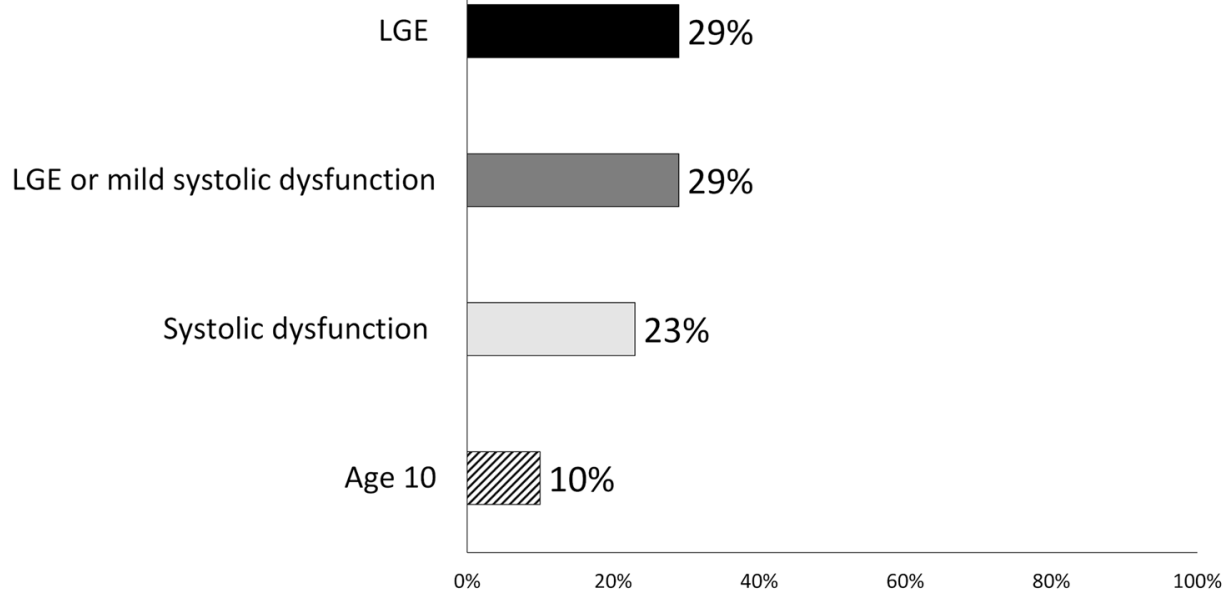


all providers (including those who have not yet implanted an ICD) was an LVEF $<35 \%$ in the presence of non-sustained ventricular tachycardia (NSVT). Three providers (10\%) would consider ICD implantation for LVEF $<35 \%$ alone and an additional two providers (6\%) would consider ICD in patients with an LVEF $<35 \%$, LGE, and NSVT. Seven providers would consider in the setting of NSVT alone (23\%).

\section{Ventricular Assist Device (VAD) and Heart Transplant}

A significant majority of providers would consider VAD as destination therapy $(n=23,74 \%)$ with an additional three providers considering VAD only as bridge to transplant $(n=3,10 \%)$. Sixteen percent $(n=5)$ of providers would not consider VAD at their institution. Seven providers (23\%) have placed an LVAD in a patient with DMD at their center, 9 providers (29\%) have placed an LVAD in a patient with Becker muscular dystrophy (BMD) at their center, and 14 providers $(45 \%)$ have placed an LVAD in a patient with another type of muscular dystrophy at their center. Sixteen $(52 \%)$ of providers would consider listing a patient with DMD for heart transplant.

\section{Discussion}

The last few years have seen an increasing focus on the impact of cardiomyopathy on long term outcomes in DMD. Recent guidelines, including the DMD Care Considerations and American Heart Association (AHA) Management of Cardiac Involvement Associated with Neuromuscular Diseases, have attempted to address gaps in data by providing expert consensus on the diagnostic and therapeutic approach to DMD-related cardiomyopathy. Despite these efforts, it is unclear how widespread the knowledge of these recommendations is and how they have been applied within the cardiology community. This report describes the current approach to diagnostics and medical therapy among members of the ACTION DMD committee. We have identified several areas of practice variation revolving around how and when to initiate diagnostic testing and medical therapy. Importantly, we also describe a significant evolution in the use of advanced cardiac therapies as multiple centers have begun to implant ICDs and VADs (Fig. 2).

This manuscript represents an initial description of the landscape of cardiac care management in the current era among ACTION members. There appears to be general consensus regarding the use of ACEi/ARB and beta-blockers among the current group, although there are some differences in the specifics of initiation. This approach is generally in keeping with what is outlined in the consensus guidelines $[8,9]$. Furthermore, the fact that the majority of providers (68\%) are initiating prophylactic therapy with ACEi/ARB

\section{a}

Provider Approach to DMD VAD Therapy

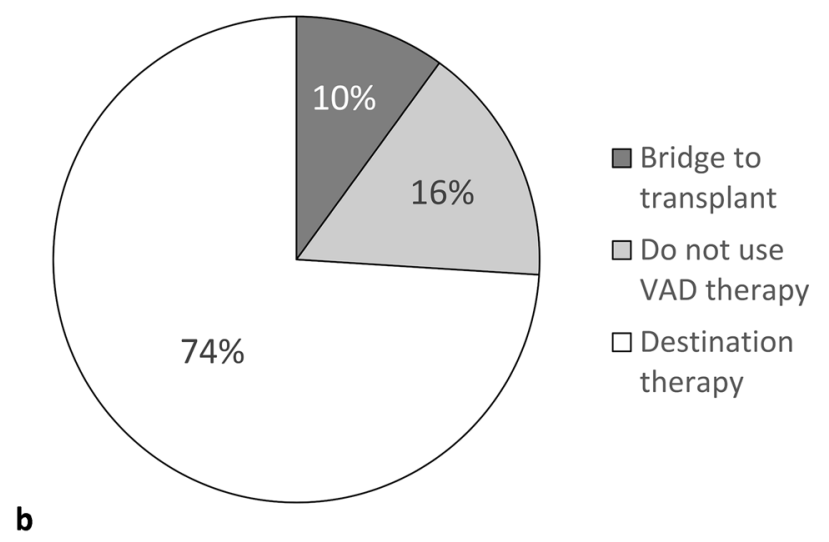

Provider Approach to ICD Therapy

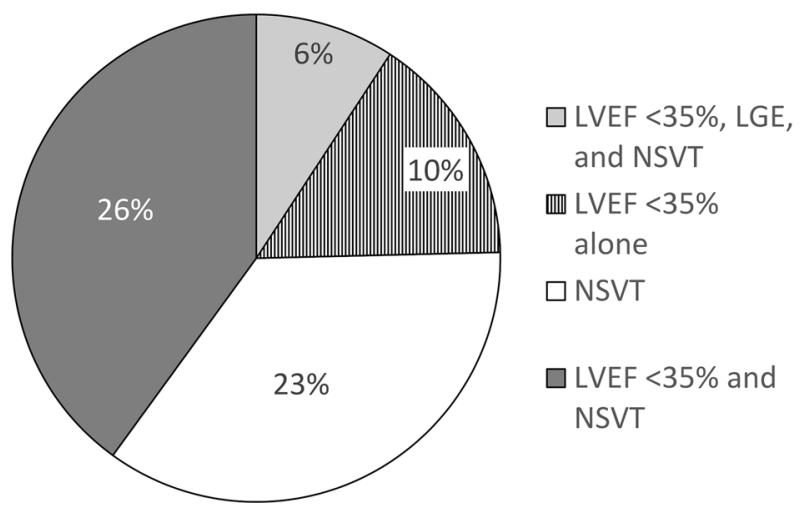

Fig. 2 Provider approach to advanced therapies in DMD. A Frequency of providers who would consider implanting a ventricular assist device in DMD according to device intent; B Provider indications for considering ICD implantation for primary prevention. ICD Implantable cardioverter defibrillators, $L G E$ Late gadolinium enhancement, $L V E F$ Left ventricular ejection fraction, NSVT Nonsustained ventricular tachycardia, $V A D$ Ventricular assist device

is notable given recent data demonstrating that prophylactic initiation is associated with higher survival and lower rates of heart failure hospitalization [6]. Initiation and use of aldosterone antagonists is more variable as just over half of providers routinely use this class of medication relatively early in the course of cardiomyopathy with the onset of LGE or systolic dysfunction. We suspect this reflects the more circumspect recommendation for this class of medication in the available guidelines. In total, understanding these practice patterns is especially notable as the data regarding efficacy of medical therapy evolves. It also highlights the gap in our understanding regarding the facilitators and barriers to achieving guideline-directed medical therapy (GDMT) both in the current state, and as important new data are published. Previous studies in adults with heart failure suggest the reasons are numerous and vary based on medication class, patient preference, clinical status, and health care provider/ 
center [16-18]. Creating the infrastructure for tracking medical therapy, understanding these factors, and creating a system for intervention and dissemination is especially important in the era of rapidly evolving medical therapy for non-DMD heart failure that will likely be employed in DMD as well [19]. We specifically did not address the use of these classes (e.g., ARNI [Angiotensin receptor-neprilysin inhibitors], sodium glucose co-transporter 2 [SGLT2] inhibitors, etc.) given the lack of data in DMD. Discussion is ongoing on how to address these data gaps and how to approach therapy in the interim. The survey also did not address the topic regarding medication dosing and titration, this group is beginning to collect data prospectively to understand these practices.

The approach to diagnostic testing was highly variable among this cohort. Cardiac MRI has come to serve a fundamental role in our understanding of the development and progression of DMD-related cardiomyopathy. The development of LGE represents a non-invasive marker of cardiac fibrosis and predates the development of systolic dysfunction $[20,21]$. As a result, progression of LGE has been used as a method to assess clinical efficacy in DMD trials assessing ACE inhibitors and aldosterone antagonists [10-12]. Despite its widespread use in research, clinical application appears more variable. This likely reflects the logistical challenges and experience necessary to obtain reliable scans in the setting of musculoskeletal disease and scoliosis as well as overall availability at a given center. The use of CMR also appears to vary by provider, as some providers use the development LGE as part of their clinical decision making (e.g., initiation of anti-fibrotic therapies, initiating rhythm monitoring/therapy, etc.) while others do not. If CMR is not being used to change or guide therapy, or requires sedation, the logistical challenges may supersede the potentially valuable clinical phenotyping data CMR can provide. Additionally, more data are needed to determine if there are long term effects of repeated gadolinium administration given reports of tissue deposition long after gadolinium exposure [22]. Individual centers have begun to decrease the frequency of LGE administration accordingly with less frequent gadolinium administration [23].

Advanced heart failure therapies, including ICDs and VADs are now being employed more widely, if infrequently, as part of heart failure management in teenagers and young adults with heart failure. The outcomes associated with the use of these therapies are very limited [24]. In recent years, there have also been case reports and series describing heart transplantation in DMD $[25,26]$. The results of this survey expand on these reports by demonstrating center based care is highly variable and sometimes completely divergent. While studies involving larger cohorts are needed to demonstrate efficacy of advanced therapies, a better understanding of the rationale for offering advanced therapies is also needed. Studying center-specific protocols, thresholds for second opinions from other centers, and the patient/family perspective will provide critical insight that will help shape a rapidly advancing field. Furthermore, in an era where long term survival is increasing and novel therapies may delay skeletal muscle disease progression, discussion regarding the indications and contraindications to transplant are warranted as just over half of centers noted they would consider transplant. A small number of patients have undergone transplant to date and understanding these outcomes in real-time would benefit patients, families, and providers as they discuss the risks, benefits, and feasibility of heart transplant, both in isolation and when compared to alternate therapies such as VAD [26].

\section{Integrating the Survey with New ACTION Initiatives}

The current survey expands on the existing literature and depicts a field in flux. Therapeutic approaches to heart failure are rapidly evolving which translates into a highly variable approach to heart failure therapy in DMD. The ACTION DMD committee has recently formed with the stated goal of improving symptom-free survival in patients with DMD. The group will strive to attain this goal with a multi-pronged approach including creation of a multi-institution database, quality improvement project focusing on timely and effective care delivery, and parent/patient engagement and advocacy. At the time of this submission, 26 centers have committed to sharing data and experience in order to achieve the stated goal (data collection officially launched in June 2021 following a delay during 2020 due to COVID-19).

The group has begun by developing an ACTION DMD database capable of integrating longitudinal, practice level data with administrative and clinical databases (e.g., Pediatric Health Information System [PHIS], United Network for Organ Sharing/Organ Procurement and Transplantation Network [UNOS/OPTN]) in addition to any existing ACTION databases (e.g., VAD database, heart failure database). This will create a data infrastructure for defining heart failure care practices and outcomes in the current era, which will then inform quality improvement projects focused on delivering effective guideline driven care. These data will then be married with qualitative or semi-quantitative data not specifically addressed or amenable to typical data collection (e.g., interviews, focus groups) to take on topics including shared decision making in rare diseases, pushing boundaries. This will be facilitated via engagement with individuals and families as well as national and international stakeholders including Parent Project Muscular Dystrophy (PPMD) in order to appreciate the broader care landscape outside of ACTION as the ultimate goal of this project is to improve outcomes 
within the field, and provide access to care which remains a broad issue for DMD patients as a whole. Engagement with non-ACTION centers, additional patient/family advocacy organizations (both local/regional and national), and cardiologists not at ACTION centers will be fundamental to improving care and ensuring cardiac care is available and delivered in an equitable manner to all patients with DMD. In fact, engagement with a broad group of stakeholders will not only help to ensure more consistent, guideline directed care, but will also inform our understanding of local and regional factors in a diverse patient cohort and how patient/ family and provider factors relate to access and care delivery.

\section{Limitations}

This survey was developed to understand the care practices of initial group of ACTION centers. This group is comprised providers and centers that generally work in tertiary care hospitals. It is unclear how these practices translate more broadly within the field. Furthermore, while the surveys seek to describe the general approach to diagnostic evaluation and therapy, granular data to confirm how this translates to practice is needed.

\section{Conclusions}

Heart failure is a leading cause of morbidity and mortality in DMD, and data regarding outcomes and cardiac disease progression are lacking. This has led to an environment where care practices are highly variable from center to center. The ACTION DMD committee has formed to understand these outcomes and to use a data driven approach to inform quality improvement projects that will focus on reducing unneeded variability and effectively delivering guideline directed care in order to improve clinical outcomes.

\section{Funding None.}

\section{Declarations}

Conflict of Interest None of the authors has any conflict of interest to disclose.

Ethical Approval This study was IRB exempt as part of the quality improvement activities of ACTION.

Informed Consent Written informed consent to participate in the study was not obtained from providers as the survey was optional and the potential for publication was discussed in the group as part of the survey.

\section{References}

1. Eagle M, Baudouin SV, Chandler C, Giddings DR, Bullock R, Bushby K (2002) Survival in Duchenne muscular dystrophy: improvements in life expectancy since 1967 and the impact of home nocturnal ventilation. Neuromuscul Disord 12:926-929

2. Kieny P, Chollet S, Delalande P, Le Fort M, Magot A, Pereon Y, Perrouin Verbe B (2013) Evolution of life expectancy of patients with Duchenne muscular dystrophy at AFM Yolaine de Kepper centre between 1981 and 2011. Ann Phys Rehabil Med $56: 443-454$

3. Landfeldt E, Thompson R, Sejersen T, McMillan HJ, Kirschner J, Lochmuller H (2020) Life expectancy at birth in Duchenne muscular dystrophy: a systematic review and meta-analysis. Eur J Epidemiol 35:643-653

4. McDonald CM, Henricson EK, Abresch RT, Duong T, Joyce NC, Hu F, Clemens PR, Hoffman EP, Cnaan A, Gordish-Dressman H, Investigators C (2018) Long-term effects of glucocorticoids on function, quality of life, and survival in patients with Duchenne muscular dystrophy: a prospective cohort study. Lancet 391:451-461

5. Van Ruiten HJ, Marini Bettolo C, Cheetham T, Eagle M, Lochmuller H, Straub V, Bushby K, Guglieri M (2016) Why are some patients with Duchenne muscular dystrophy dying young: An analysis of causes of death in North East England. Eur J Paediatr Neurol 20:904-909

6. Porcher R, Desguerre I, Amthor H, Chabrol B, Audic F, Rivier F, Isapof A, Tiffreau V, Campana-Salort E, Leturcq F, TufferyGiraud S, Ben Yaou R, Annane D, Amedro P, Barnerias C, Becane HM, Behin A, Bonnet D, Bassez G, Cossee M, de La Villeon G, Delcourte C, Fayssoil A, Fontaine B, Godart F, Guillaumont S, Jaillette E, Laforet P, Leonard-Louis S, Lofaso F, Mayer M, Morales RJ, Meune C, Orlikowski D, Ovaert C, Prigent H, Saadi M, Sochala M, Tard C, Vaksmann G, WaltherLouvier U, Eymard B, Stojkovic T, Ravaud P, Duboc D, Wahbi K (2021) Association between prophylactic angiotensin-converting enzyme inhibitors and overall survival in Duchenne muscular dystrophy-analysis of registry data. Eur Heart J:

7. McNally EM, Kaltman JR, Benson DW, Canter CE, Cripe LH, Duan D, Finder JD, Hoffman EP, Judge DP, Kertesz N, Kinnett K, Kirsch R, Metzger JM, Pearson GD, Rafael-Fortney JA, Raman SV, Spurney CF, Targum SL, Wagner KR, Markham LW (2015) Contemporary cardiac issues in duchenne muscular dystrophy. Circulation 131:1590-1598

8. Birnkrant DJ, Bushby K, Bann CM, Alman BA, Apkon SD, Blackwell A, Case LE, Cripe L, Hadjiyannakis S, Olson AK, Sheehan DW, Bolen J, Weber DR, Ward LM, Group DMDCCW (2018) Diagnosis and management of Duchenne muscular dystrophy, part 2: respiratory, cardiac, bone health, and orthopaedic management. Lancet Neurol 17:347-361

9. Feingold B, Mahle WT, Auerbach S, Clemens P, Domenighetti AA, Jefferies JL, Judge DP, Lal AK, Markham LW, Parks WJ, Tsuda T, Wang PJ, Yoo SJ, American Heart Association Pediatric Heart Failure Committee of the Council on Cardiovascular Disease in the Y, Council on Clinical C, Council on Cardiovascular R, Intervention, Council on Functional G, Translational B, Stroke C (2017) Management of cardiac involvement associated with neuromuscular diseases: a scientific statement From the American Heart Association. Circulation 136:e200-e231

10. Silva MC, Magalhaes TA, Meira ZM, Rassi CH, Andrade AC, Gutierrez PS, Azevedo CF, Gurgel-Giannetti J, Vainzof M, Zatz M, Kalil-Filho R, Rochitte CE (2017) Myocardial fibrosis progression in Duchenne and Becker muscular dystrophy: a randomized clinical trial. JAMA Cardiol 2:190-199 
11. Raman SV, Hor KN, Mazur W, Halnon NJ, Kissel JT, He X, Tran T, Smart S, McCarthy B, Taylor MD, Jefferies JL, Rafael-Fortney JA, Lowe J, Roble SL, Cripe LH (2015) Eplerenone for early cardiomyopathy in Duchenne muscular dystrophy: a randomised, double-blind, placebo-controlled trial. Lancet Neurol 14:153-161

12. Raman SV, Hor KN, Mazur W, Cardona A, He X, Halnon N, Markham L, Soslow JH, Puchalski MD, Auerbach SR, Truong U, Smart S, McCarthy B, Saeed IM, Statland JM, Kissel JT, Cripe LH (2019) Stabilization of early duchenne cardiomyopathy with aldosterone inhibition: results of the multicenter AIDMD trial. J Am Heart Assoc 8:e013501

13. Wittlieb-Weber CA, Villa CR, Conway J, Bock MJ, Gambetta KE, Johnson JN, Lal AK, Schumacher KR, Law SP, Deshpande SR, West SC, Friedland-Little JM, Lytrivi ID, McCulloch MA, Butts RJ, Weber DR, Knecht KR (2019) Use of advanced heart failure therapies in Duchenne muscular dystrophy. Prog Pediatr Cardiol 53:11-14

14. Spurney C, Shimizu R, Morgenroth LP, Kolski H, GordishDressman H, Clemens PR, Investigators C (2014) Cooperative International Neuromuscular Research Group Duchenne Natural History Study demonstrates insufficient diagnosis and treatment of cardiomyopathy in Duchenne muscular dystrophy. Muscle Nerve 50:250-256

15. Lorts A, Smyth L, Gajarski RJ, VanderPluym CJ, Mehegan M, Villa CR, Murray JM, Niebler RA, Almond CS, Thrush P, O'Connor MJ, Conway J, Sutcliffe DL, Lantz JE, Zafar F, Morales DLS, Peng DM, Rosenthal DN (2020) The creation of a pediatric health care learning network: The ACTION quality improvement collaborative. ASAIO J 66:441-446

16. Greene SJ, Fonarow GC, DeVore AD, Sharma PP, Vaduganathan M, Albert NM, Duffy CI, Hill CL, McCague K, Patterson JH, Spertus JA, Thomas L, Williams FB, Hernandez AF, Butler J (2019) Titration of medical therapy for heart failure with reduced ejection fraction. J Am Coll Cardiol 73:2365-2383

17. Cowie MR, Schope J, Wagenpfeil S, Tavazzi L, Bohm M, Ponikowski P, Anker SD, Filippatos GS, Komajda M, Investigators Q (2021) Patient factors associated with titration of medical therapy in patients with heart failure with reduced ejection fraction: data from the QUALIFY international registry. ESC Heart Fail:

18. Komajda M, Cowie MR, Tavazzi L, Ponikowski P, Anker SD, Filippatos GS, Investigators Q (2017) Physicians' guideline adherence is associated with better prognosis in outpatients with heart failure with reduced ejection fraction: the QUALIFY international registry. Eur J Heart Fail 19:1414-1423

19. Bhatt AS, Abraham WT, Lindenfeld J, Bristow M, Carson PE, Felker GM, Fonarow GC, Greene SJ, Psotka MA, Solomon SD,
Stockbridge N, Teerlink JR, Vaduganathan M, Wittes J, Fiuzat M, O'Connor CM, Butler J (2021) Treatment of HF in an era of multiple therapies: statement from the HF collaboratory. JACC Heart Fail 9:1-12

20. Silva MC, Meira ZM, Gurgel Giannetti J, da Silva MM, Campos AF, Barbosa Mde M, Starling Filho GM, Ferreira Rde A, Zatz M, Rochitte CE (2007) Myocardial delayed enhancement by magnetic resonance imaging in patients with muscular dystrophy. J Am Coll Cardiol 49:1874-1879

21. Tandon A, Villa CR, Hor KN, Jefferies JL, Gao Z, Towbin JA, Wong BL, Mazur W, Fleck RJ, Sticka JJ, Benson DW, Taylor MD (2015) Myocardial fibrosis burden predicts left ventricular ejection fraction and is associated with age and steroid treatment duration in duchenne muscular dystrophy. J Am Heart Assoc 4:e001338

22. Flood TF, Stence NV, Maloney JA, Mirsky DM (2017) Pediatric brain: repeated exposure to linear gadolinium-based contrast material is associated with increased signal intensity at unenhanced T1-weighted MR imaging. Radiology 282:222-228

23. Lang SM, Alsaied T, Moore RA, Rattan M, Ryan TD, Taylor MD (2019) Conservative gadolinium administration to patients with Duchenne muscular dystrophy: decreasing exposure, cost, and time, without change in medical management. Int $\mathrm{J}$ Cardiovasc Imaging 35:2213-2219

24. Perri G, Filippelli S, Adorisio R, Iacobelli R, Iodice F, Testa G, Paglietti MG, D'Amario D, Massetti M, Amodeo A (2017) Left ventricular assist device as destination therapy in cardiac endstage dystrophinopathies: Midterm results. J Thorac Cardiovasc Surg 153:669-674

25. Piperata A, Bottio T, Toscano G, Avesani M, Vianello A, Gerosa $\mathrm{G}$ (2020) Is heart transplantation a real option in patients with Duchenne syndrome? inferences from a case report. ESC Heart Fail 7:3198-3202

26. Wells D, Rizwan R, Jefferies JL, Bryant R 3rd, Ryan TD, Lorts A, Chin C, Zafar F, Morales DL (2020) Heart transplantation in muscular dystrophy patients: is it a viable option? Circ Heart Fail 13:e05447

Publisher's Note Springer Nature remains neutral with regard to jurisdictional claims in published maps and institutional affiliations.

\section{Authors and Affiliations}

\section{Chet Villa ${ }^{1}$. Scott R. Auerbach ${ }^{2} \cdot$ Neha Bansal $^{3} \cdot$ Brian F. Birnbaum $^{4} \cdot$ Jennifer Conway $^{5} \cdot$ Paul Esteso $^{6}$. Katheryn Gambetta ${ }^{7}$. E. Kevin Hall ${ }^{8}$. Beth D. Kaufman ${ }^{9}$. Sonya Kirmani ${ }^{10}$ - Ashwin K. Lal ${ }^{11}$ • Hugo R. Martinez ${ }^{12}$. Deipanjan Nandi ${ }^{13}$. Matthew J. O'Connor ${ }^{14}$. John J. Parent ${ }^{15}$. Frank J. Raucci ${ }^{16}$. Renata Shih ${ }^{17}$. Svetlana Shugh ${ }^{18}$. Jonathan H. Soslow ${ }^{19} \cdot$ Hari Tunuguntla ${ }^{20}$. Carol A. Wittlieb-Weber ${ }^{14} \cdot$ Kathi Kinnett $^{21} \cdot$ Linda Cripe $^{13}$}

1 Cincinnati Children's Hospital Medical Center, University of Cincinnati College of Medicine, 3333 Burnet Ave, MLC 2003, Cincinnati, OH 45229, USA

2 Department of Pediatrics, Division of Cardiology, University of Colorado, Denver Anschutz Medical Campus, Children's Hospital Colorado Aurora, Aurora, CO, USA

3 Division of Pediatric Cardiology, Children's Hospital at Montefiore, Albert Einstein College of Medicine, Bronx, NY, USA
4 Children's Mercy Hospital and Clinics, Kansas City, MO, USA

5 Stollery Children's Hospital, Edmonton, AB T6G 2B7, Canada

6 Boston Children's Hospital, Boston, MA, USA

7 Ann and Robert H Lurie Children's Hospital, Chicago, IL, USA 
8 Yale New Haven Children's Hospital, Yale University School of Medicine, New Haven, CT, USA

9 Department of Pediatrics (Cardiology), Stanford University School of Medicine, Palo Alto, CA, USA

10 Duke Children's Pediatric and Congenital Heart Center, Duke Children's Hospital, Durham, NC, USA

11 Division of Pediatric Cardiology, Primary Children's Hospital, University of Utah, Salt Lake City, UT, USA

12 The Heart Institute at Le Bonheur Children's Hospital and The University of Tennessee Health Science Center, Memphis, TN, USA

13 Nationwide Children's Hospital, Columbus, OH, USA

14 Division of Cardiology, Department of Pediatrics, University of Pennsylvania School of Medicine, Children's Hospital of Philadelphia, Philadelphia, PA, USA
15 Riley Hospital for Children, Indiana University, Indianapolis, IN, USA

16 Children's Hospital of Richmond, Virginia Commonwealth University Health System, Richmond, VA, USA

17 Congenital Heart Center, University of Florida, Gainesville, FL, USA

18 Heart Institute, Joe DiMaggio Children's Hospital, Hollywood, FL, USA

19 Department of Pediatrics, Thomas P. Graham Division of Pediatric Cardiology, Monroe Carell Jr. Children's Hospital at Vanderbilt, Nashville, TN, USA

20 Department of Pediatrics, Baylor College of Medicine, Houston, TX, USA

21 Parent Project Muscular Dystrophy, Hackensack, NJ, USA 